\title{
Taking a View of Input-Output Process to Modeling Customer Purchase Behavior: A Case Study for Hotel Accommodation
}

\author{
Hui Hsin Huang \\ Department of Business Administration, Aletheia University, New Taipei City, Taiwan \\ Email address: \\ hoyasophia@gmail.com
}

\section{To cite this article:}

Hui Hsin Huang. Taking a View of Input-Output Process to Modeling Customer Purchase Behavior: A Case Study for Hotel Accommodation. International Journal of Hospitality \& Tourism Management. Vol. 2, No. 1, 2018, pp. 8-12. doi: 10.11648/j.ijhtm.20180201.12

Received: August 24, 2018; Accepted: September 18, 2018; Published: October 24, 2018

\begin{abstract}
This paper takes a view of an input-output process to describe the relationship between customer purchase satisfaction and repeat purchase intention. The satisfaction (SF) is considered as a function which is evaluated by the discrepancy (d) between the ideal position (I) of the product attribute and the position (P) which customer perceived in regard to attribute. The repeat purchase intention is predict by the variable "black box" of transforming process from satisfaction (which is based on the system approach theory). Then a case study with the taboo marketing for hotel accommodation is demonstrated to make application of the input-output model. In the case, the variable of fear is considered as the transforming process and there are 300 samples is conduct in the experience design to refer the model. Half of sample is for parameter estimation and another is for model validation. The results show it is good fitness between predicting data and real data.
\end{abstract}

Keywords: Satisfaction, Repeat Purchase Intention, The System Approach Theory, Input-Output Process, Ideal Point

\section{Introduction}

In the marketing or consumer behavior area, the casual relationship between customer's satisfaction and purchase are discussed in many academic studies. Customers' satisfaction is viewed as one of the crucial factors to predict repeat purchase. Previous research found that if customer feels more satisfaction will show less switch tendency then increase the chance of repeat purchase intention. But does the satisfaction exactly trigger the repeat purchase intention directly?

Some research finds that there are other moderator or mediator variables such as perceived value or psychological factors will accompany with the impact of satisfaction to repeat purchase intention. If the customer purchase behavior is considered as a process which includes some variables of input, mediate and finally output. Then, the customer psychological mechanism plays an important role on transforming the input of satisfaction to output of purchase intention. In this paper, the author takes a view of point on a macroscale to consider the framework based on the system approach of management to portray how the satisfaction can influence the repeat purchase intention.
For the research model construction, numerous researches use applied statistics and data mining to develop a numbers of models that attempt to either explain or predict the marketing problem especially in the topic of customer behavior. A rich literature on statistical models for customer-base analysis make use of data in a firm's own transaction database to forecast customer behavior $([1,2,16])$. In this paper, we use customer-base analysis of statistic model to uncover latent patterns of customer psychological mechanism and construct the relationships among satisfaction(input)- psychological mechanism (transformation)-repeat purchase intention (output) [16].

This paper is organized as following, first we will make the literature review and concept description. Secondly, the model of input and output will be demonstrated. The detail of every factor of this model will be portrayed. Thirdly, the empirical data is used to estimate the parameters and to make application. The model validation are shown in this section. Finally, the conclusions are made. 


\section{Literature Review and Model Construction}

\subsection{The System Approach Theory in Management}

In the system approach theory in management, organizations are viewed as an open or closed system depend on which are affected by their environment or not. An open system is influenced by its environment consists of three essential elements, input, throughput or transformation process and output. The organizations receive the sources such as raw material, human resources or capital, referred to as inputs. The inputs are transformed to employees' work activities or management activities. Then they yield the products or service as output.

Based on the system approach theory, we propose the customer's behavior model through the relationship of the connection between satisfaction and repeat purchase intention as a series process of input-transformation- output(please see figure 1).

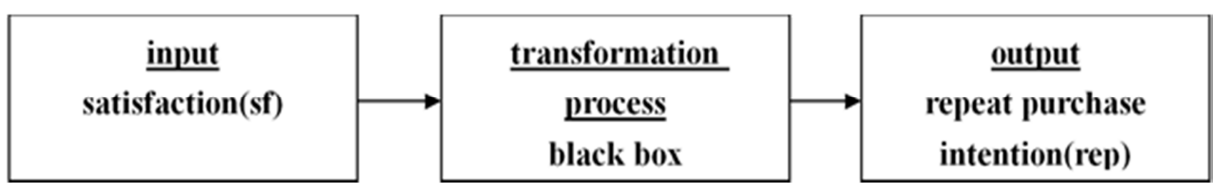

Figure 1. The system approach process.

\subsection{Input: Customers' Satisfaction}

The customer satisfaction as essential to gaining sustainable growth and competitive advantages ([7, 8, 22]). It has a direct impact on primary source of future revenue streams for most companies. The ideal point conceptualization as one aspect of customer satisfaction represents the optimal product performance a consumer ideally would hope for. It reflects what performance "can be." It may be based on previous product experiences, learning from advertisements and word-of-mouth communication [7]. Ideal product performance is one of the approaches to conceptualizing a pre-experience comparison standard have been suggested in satisfaction literature. Thus, ideal point models enable managers to examine how close each product is to a consumer's ideal point.

In the past fifty years, various ideal point models have been introduced into the psychology and marketing area. Such as Fornell et al. [10] use the psychological distance between product performance and customer ideal point to estimate customer overall satisfactions. And the measurement of ideal standard in the service quality research is considered as similar to evaluate SERVQUAL expectations (which is the service quality questionnaire and is often used in service industry) to the customer satisfaction or dissatisfaction ([17], [7]).

According to the literature review, deriving from the ideal point models of consumer preference and choice [7], customer satisfaction is an evaluation as a function of discrepancies from one's ideal point.

Thus, based on the ideal point theory [9], we consider the satisfaction (SF) is a function which is evaluated by the discrepancy (d) between the ideal position (I) of the customer with regard attribute of the product and the position (P) which customer perceived in regard to attribute. It can be demonstrated as.

$$
D=|I-P|
$$

As the discrepancy with respect to the particular attribute increases, evaluation decreases monotonically.

The initial differences from one's own position will be associated with a larger decrease in evaluation than additional differences.

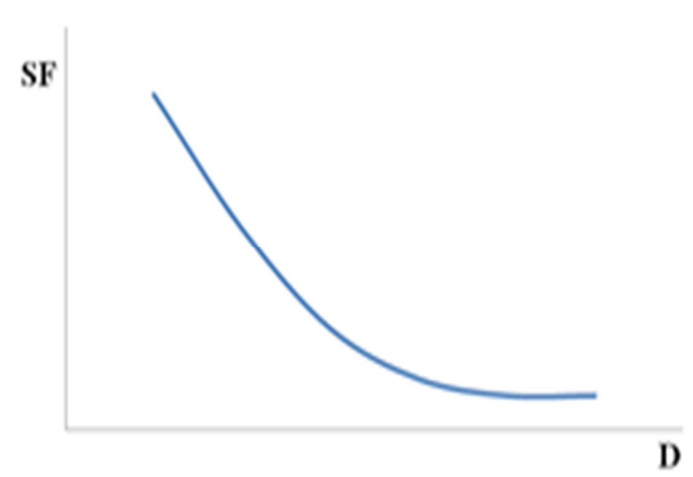

Figure 2. The relationship between satisfaction and discrepancy.

Thus, we consider the function discrepancy (d) between the ideal position (I) of satisfaction $\mathrm{SF}(\mathrm{d})$ is an exponential distribution with its pdf as.

$$
S F(d)=\lambda \cdot \exp (-\lambda d)
$$

In which $\lambda$ is a parameter which indicates the weight of the importance with attribute that customer perceived.

\subsection{Transformation Process: Black Box}

The mechanism of transformation process connects the input and output factors, sometimes can refer it as a "black box" which is an abstraction representing a class of concrete open system which can be viewed solely in terms of its stimuli inputs and output reactions [3]. A black box is based on the "explanatory principle", the hypothesis of a causal relation between the input and the output [12]. In philosophy and psychology, the school of behaviorism sees the human mind as a black box [11]. Thus, based on this view of point, we consider the other factors that will impact the satisfaction to purchase intention as the customers' psychological process which is a black box $(\mathrm{x})$. Thus, the satisfaction function is also included this transformation process as $\operatorname{SF}(d, x)$. 


\subsection{Customers Repeat Purchase Intention}

Customers repeat purchase intention refers to the subjective probability that a customer will continue to purchase a product from the same brand or store [6]. It is also the degree to which customers are willing to purchase the same product or service and it is a simple, objective, and observable predictor of future buying behavior ([7, 17], [20]). Customer repeat-purchase intention is critical to store profitability.

Many studies find that customer satisfaction is positively related to repeat-purchase intention $([7,3,6])$, and is a determinant of long-term repeat-purchase ([7, 19]). The higher cumulative satisfaction can lead to higher repeat-purchase intention and frequency $([7,18,19])$. Thus, we demonstrate that repeat the purchase intention(RPI) is a function of satisfaction. Beside satisfaction, we base on the system approach theory to include the variable "black box (x)" of transforming process in predict the repeat purchase intention. Then repeat the purchase intention(RPI) is a function(h) of $\mathrm{SF}(\mathrm{d}, \mathrm{x})$ as.

$$
R P I \sim h(S F(d, x))
$$

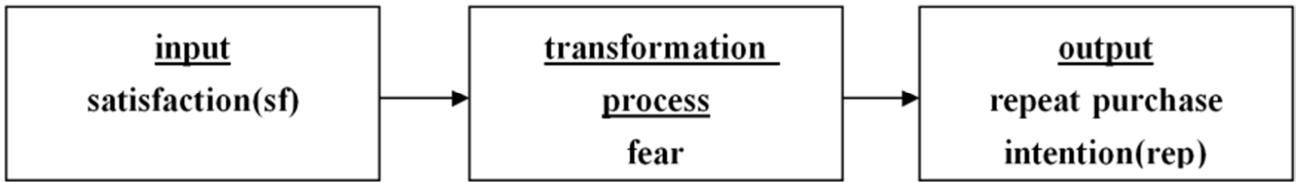

Figure 3. The system approach process of case study.

Thus, in this case, we treat the variable "fear" as a random variable $f$ to represent the concept of black box(x). Then according to (3), we can obtain.

$$
R P I \sim h(S F(d, f))
$$

\subsection{The Sample and Analysis Process}

There are 300 recruited participates for the experiment. In the first step, participates were told to imagine that they were visiting Bali for summer vacation and presented with a description of a resort hotel located near a beautiful beach with luxurious facilities, such as a spa. Next, they answered a hotel satisfaction questionnaire.

In the second step, 300 participants are distributed randomly into three different scenarios. These three scenarios represent a low, middle, and high death-taboo context, respectively. Finally, participants reported their level of fear and finally the repeat purchase intention with the hotel.

Satisfaction and fear

The results find that the relationship between satisfaction and fear is show in figure

\section{A Cause Study: The Taboo Marketing for Hotel Accommodation}

We demonstrate a case study to make application of our proposed model. The case is used by Huang [12] in which the topic of taboo marketing is studied by exploring the variance among customers' satisfaction, fearing and repurchase intention in hotel accommodations. This case is used experience method to consider three death taboo scenarios: (1) customers staying at the hotel find information on the Internet about someone who has died at the hotel; (2) customers encounter strange phenomena after staying at the hotel; (3) customers both find such information on the Internet and encounter strange phenomena.

Thus the variable, "fear" is a customer feeling of psychological mechanism when measuring their satisfaction (input) to repeat purchase intention (output) of hotel accommodations. This variable is like a black box which transforms the input to output can cause some unknown impact. It means under this circumstance, customer satisfaction does not directly lead to repeat purchase intention when the level of fear feeling is unknown. The figure of input-transformation- output can be portray as.

\section{rocess intention(rep)}


variable is taken as an example as the transformation between satisfaction and repeat purchase intention. Thus, deriving from (2), (4) and (5), we can obtain.

$$
S F(d, f)=\lambda \cdot \exp (-\lambda d) \frac{1}{\sqrt{2 \pi \sigma^{2}}} \exp \left(\frac{(f-\mu)^{2}}{\sigma^{2}}\right)
$$

In which satisfaction is a joint density with the random variable $\mathrm{d}$ and $\mathrm{f}$.

\subsection{The Repeat Purchase Intention and Satisfaction}

The analysis results from the experiment method, we can find the a linear relationship between repeat purchase intention and satisfaction. It shows in figure 3 .

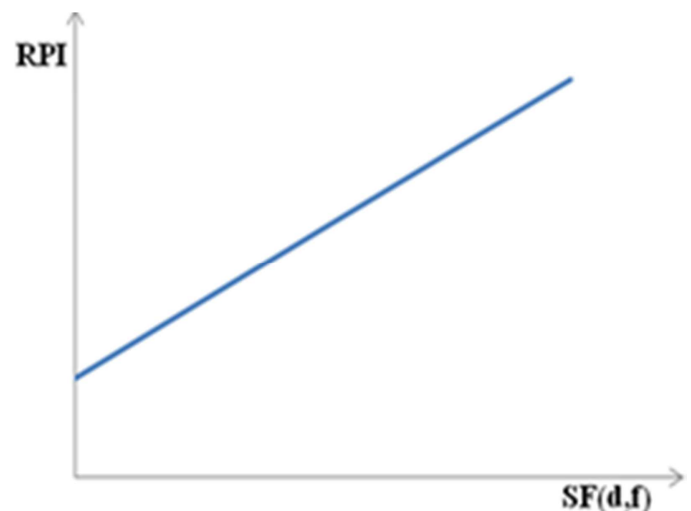

Figure 5. The relationship between repeat purchase intention and satisfaction.

This result is from regression analysis. We can portray it as equation (7).

$$
R P I=\alpha_{0}+\alpha_{1} S F(d, f)
$$

\subsection{The Repeat Purchase Intention and Fear}

Based on the results of analysis, we can find that the middle level of fear may case higher level of repeat purchase intention but the lower level of repeat purchase intention is happened in the higher or lower level of fear situation. It can show in figure 4 .

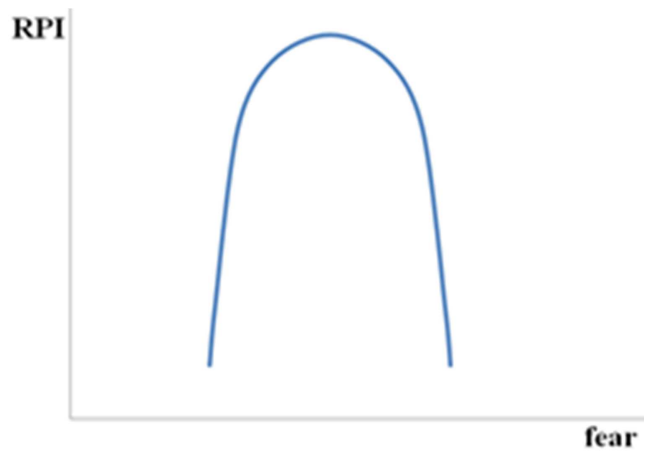

Figure 6. The relationship between repeat purchase intention and fear.

Thus, base on this relationship between fear and repeat purchase intention, we consider that repeat purchase intention is a function of fear which is a random variable and follows normal distribution with parameterwand $\tau 2$.

$$
R P I(f)=\frac{1}{\sqrt{2 \pi \tau^{2}}} \exp \left(\frac{(f-\omega)^{2}}{\tau^{2}}\right)
$$

\section{The Analysis and Results}

We separate the 300data into two parts. One is for parameters estimation of the proposed model. Another is for model validation. The process is as following: (1) We use 150data to estimate the parameters of models. (2) Then, use the results to figure out the model. (3) To put another 150data in the model to predict the dependent variable. (4) Finally, to calculate how close the prediction results and the real data.

\subsection{The Parameters Estimation}

We use maximum likelihood estimation (MLE) to estimate the parameters of equation (6), (7) and (8). The results are shown in table 1 .

Table 1. The results of parameters estimation.

\begin{tabular}{lllllll}
\hline $\boldsymbol{\lambda}$ & $\boldsymbol{\mu}$ & $\boldsymbol{\sigma 2}$ & $\boldsymbol{\alpha 0}$ & $\boldsymbol{\alpha 1}$ & $\boldsymbol{\omega}$ & $\boldsymbol{\tau} \mathbf{2}$ \\
\hline 3.7892 & 4.235 & 0.9987 & 3.616 & 0.009 & -0.343 & 1.298 \\
\hline
\end{tabular}

\subsection{The Model Validation}

We calculate how close the prediction results and the real data. The root-mean-square deviation (RMSD) is used by computing the mean of total distance between the prediction data(R1) and the real data(R2). It can be demonstrate in $\sqrt{\sum_{j=1}^{n}\left(R_{1 j}-R_{2 j}\right)^{2}} / \mathrm{n}$. The results shows $\mathrm{RMSD}=0.835$ which is smaller than 1 . Thus the fitness is acceptable.

\section{The Onclusion}

This research takes a new view of point to consider satisfaction and repeat purchase intention as an input-output process and use stochastic concepts to form the model to portray this process. The taboo marketing for hotel accommodation is used for case study in which the variable "fear" is consider as the black box variable of transformation process in input-output series. The experiment method is conduct to collect data for parameter estimation and model validation. The result shows acceptable fitness. Thus, in the future, the managers can use the view of point of input-output process to explore customers' satisfaction and repeat purchase intention. In this process, the "black box" as the transformation is an opened setting which can provide the researches or managers to substitute the suitable variable into it.

For the future research, the black box is depended on the research topic and allows more than one variables. Thus the proposed model is flexible and can discuss extended relationships between satisfaction and repeat purchase intention. The researches can also consider other distribution for example log normal distribution to describe each variable. 


\section{References}

[1] Abe, Makoto (2009), "Counting Your Customers" One by One: A Hierarchical Bayes Extension to the Pareto/NBD Model," Marketing Science, 28 (May June), 541-553.

[2] Batislam, Meltem Denizel and Alpay Filiztekin (2007), Empirical Validation and Comparison of Models for Customer Base Analysis," International Journal of Research in Marketing, 24(September), 201-209.

[3] Brady, M. K., Robertson, C. J. and Cronin, J. J. (2001), "Managing behavioral intentions in diverse cultural environments: an investigation of service quality, service value and satisfaction for American and Ecuadorian fast-food customers", Journal of International Management, Vol. 7 No. 2, pp. 129-149.

[4] Bunge, Mario; "A general black-box theory", Philosophy of Science, Vol. 30, No. 4, 1963, pp. 346-358.

[5] Chao-Min Chiu, Eric T. G. Wang, Yu-Hui Fang \& Hsin-Yi Huang (2014). Understanding customers' repeat purchase intentions in B2C e-commerce: the roles of utilitarian value, hedonic value and perceived risk. Information Systems Journal $24,85-114$.

[6] Cronin, J. J., Brady, M. K. and Hult, G. T. M. (2000), "Assessing the effects of quality, value, and customer satisfaction on consumer behavioral intentions in service environments", Journal of Retailing, Vol. 76 No. 2, pp. 193-218.

[7] Tse, K. D. and Wilton, C. P. (1988). Models of Consumer Satisfaction Formation: An Extension. Journal of Marketing Research, Vol. 25, No. 2, pp. 204-212.

[8] Deng, Z., Lu, Y., Wei, K. K. and Zhang, J. (2010), "Understanding customer satisfaction and loyalty: an empirical study of mobile instant messages in China", International Journal of Information Management, Vol. 30 No. 4, pp. 298-300.

[9] Einhorn, J. H. and Gonedes, J. N.. (1971) An Exponential Discrepancy Model for Attitude Evaluation. Behavioral Science. Volume 16, pp. 152-157.

[10] Fornell, C., Johnson, M. D., Anderson, E.., Cha, W. J. (1996), The American Customer Satisfaction Index: Nature, Purpose, and Findings, Journal of Marketing, 60 (4), pp. 7-18.

[11] Friedenberg, Jay; and Silverman, Gordon; Cognitive Science: An Introduction to the Study of Mind. "Mind as a Black Box: The Behaviorist Approach", pp. 85-88, Sage Publications, 2006.
[12] Glanville, Ranulph; "Black Boxes", Cybernetics and Human Knowing, 2009, pp. 153-167.

[13] Haksik Lee Yongki Lee Dongkeun Yoo, (2000), "The determinants of perceived service quality and its relationship with satisfaction", Journal of Services Marketing, Vol. 14 Iss 3 pp. 217-231.

[14] Huang, H. H. (2014). Explorative study on the concept of mind shares: confidence, resistance and loyalt. Expert Journal of Marketing, 2(1), 15-27.

[15] Huang, Hui-Hsin (2017) The Consumer Purchase Behavior in Taboo Marketing. Working Paer (April 8, 2017), Available at SSRN: https://ssrn.com/abstract $=2929221$

[16] Jerath, Kinshuk, Fader, S. Peter, Hardie, G. S. Bruce. (2013). Customer-Base Analysis on a $\backslash$ Data Diet": Model Inference Using Repeated Cross-Sectional Summary (RCSS) Data. Working paper.

[17] Lin, J. S. C. and Liang, H. Y. (2011), "The influence of service environments on customer emotion and service outcomes", Managing Service Quality, Vol. 21 No. 4, pp. 350-372.

[18] Maxham, J. G. III and Netemeyer, R. G. (2002), "Modeling customer perceptions of complaint handling over time: the effects of perceived justice on satisfaction and intent", Journal of Retailing, Vol. 78 No. 4, pp. 239-252.

[19] Ranaweera, C. and Prabhu, J. (2003), "On the relative importance of customer satisfaction and trust as determinants of customer retention and positive word of mouth", Journal of Targeting, Measurement and Analysis for Marketing, Vol. 12 No. 1, pp. 82-90.

[20] Seiders, K., Voss, G. B., Grewal, D. and Godfrey, A. L. (2005), "Do satisfied customers buy more? Examining moderating influences in a retailing context", Journal of Marketing, Vol. 69, No. 4, pp. 26-43.

[21] Teas, R. K. (1993), “Expectations, performance evaluation, and consumers' perceptions of quality", Journal of Marketing, Vol. 57, October, pp. 18-34.

[22] Udo, G. J., Bagchi, K. K. and Kirs, P. J. (2010), “An assessment of customers' e-service quality perception, satisfaction and intention", International Journal of Information Management, Vol. 30 No. 6, pp. 481-492.

[23] Ying-Feng Kuo, Tzu-Li Hu, Shu-Chen Yang, (2013), "Effects of inertia and satisfaction in female online shoppers on repeat-purchase intention :The moderating roles of word-of-mouth and alternative attraction", Managing Service Quality: An International Journal, Vol. 23 Iss 3 pp. 168 - 187. 